Article

\title{
Synthesis of Poly( $\varepsilon$-caprolactone)-Based Miktoarm Star Copolymers through ROP, SA ATRC, and ATRP
}

\author{
Venkatesan Sathesh ${ }^{1}$, Jem-Kun Chen ${ }^{2}$, Chi-Jung Chang ${ }^{3}$, Junko Aimi ${ }^{4}$, Zong-Cheng Chen ${ }^{1}$, \\ Yu-Chih Hsu ${ }^{1}$, Yi-Shen Huang ${ }^{1}$ and Chih-Feng Huang 1,5,* (D) \\ 1 Department of Chemical Engineering, National Chung Hsing University, 145 Xingda Road, South District, \\ Taichung 40227, Taiwan; satheshyadav10@gmail.com (V.S.); g101065010@gmail.com (Z.-C.C.); \\ berry00713@gmail.com (Y.-C.H.); yishen617@gmail.com (Y.-S.H.) \\ 2 Department of Materials Science and Engineering, National Taiwan University of Science and Technology, \\ 43 Sec. 4, Keelung Road, Taipei 10607, Taiwan; jkchen@mail.ntust.edu.tw \\ 3 Department of Chemical Engineering, Feng Chia University, 100 Wenhwa Road, Seatwen District, \\ Taichung 40724, Taiwan; changcj@fcu.edu.tw \\ 4 Molecular Design \& Function Group, Research Center for Functional Materials, National Institute for \\ Materials Science, 1-2-1 Sengen, Tsukuba, Ibaraki 305-0047, Japan; AIMI.Junko@nims.go.jp \\ 5 Research Center for Sustainable Energy and Nanotechnology, National Chung Hsing University, \\ 145 Xingda Road, South District, Taichung 40227, Taiwan \\ * Correspondence: HuangCF@dragon.nchu.edu.tw; Tel.: +886-4-2284-0510
}

Received: 7 July 2018; Accepted: 30 July 2018; Published: 2 August 2018

\begin{abstract}
The synthesis of novel branched/star copolymers which possess unique physical properties is highly desirable. Herein, a novel strategy was demonstrated to synthesize poly( $\varepsilon$-caprolactone) (PCL) based miktoarm star ( $\mu$-star) copolymers by combining ring-opening polymerization (ROP), styrenics-assisted atom transfer radical coupling (SA ATRC), and atom transfer radical polymerization (ATRP). From the analyses of gel permeation chromatography (GPC), proton nuclear magnetic resonance $\left({ }^{1} \mathrm{H} N \mathrm{NMR}\right)$, and matrix-assisted laser desorption/ionization time-of-flight mass spectrometry (MALDI-TOF MS), well-defined PCL- $\mu$-PSt (PSt: polystyrene), and PCL- $\mu$-PtBA (PtBA: poly(tert-butyl acrylate) $\mu$-star copolymers were successfully obtained. By using atomic force microscopy (AFM), interestingly, our preliminary examinations of the $\mu$-star copolymers showed a spherical structure with diameters of ca. 250 and $45 \mathrm{~nm}$, respectively. We successfully employed combinations of synthetic techniques including ROP, SA ATRC, and ATRP with high effectiveness to synthesize PCL-based $\mu$-star copolymers.
\end{abstract}

Keywords: miktoarm star copolymers; ring-opening polymerization; styrenics-assisted atom transfer radical coupling; atom transfer radical polymerization

\section{Introduction}

In the past decades, an unprecedented range of (co)polymers were synthesized via various living polymerizations (LPs) containing ring opening (metathesis) polymerization ( $R O(M) P)[1-3]$, reversible-deactivation radical polymerization (RDRP) [4-10], chain-growth condensation polymerization (CGCP) [11-16], and ionic polymerization [17-20]. Among these various methods of LPs, RDRP is one of the most powerful and facile tools, mainly comprising reversible addition-fragmentation chain transfer (RAFT) polymerization [21-24], nitroxide-mediated radical polymerization (NMRP) [5], and atom transfer radical polymerization (ATRP) [25,26], to create diverse polymeric architectures. Thus, polymer science has seen the emergence of various novel polymer architectures-such as homo/block star (co)polymers, dumbbell/H-shape branched copolymers, dendritic copolymers, and star copolymers-for a variety of applications. Among the nonlinear 
polymers, the synthesis of star or star-shape (co)polymers are in particular of great interests because of the structural flexibility of arm designs and the diversity of the central core moieties to afford star homo/random/block/gradient copolymers, miktoarm star copolymer, etc. Thus, there is a high demand to achieve a high degree of control over the polymer architectures via facile and inexpensive procedures.

Star polymers are generally synthesized through "grafting onto", "core-first", or "arm-first" methods [27-29]. In the "grafting onto" strategy, convergent reactions of polymer chains with a reactive chain end group and a multi-functional core are quantitatively proceeded to afford star polymers. The drawback of this method comes from the mobility of the polymer chains, for example chain rigidity and high molecular weight, etc. that lead to slow and inefficient reactions. A facile and efficient organic reaction is in high demand. In the "core-first" strategy, an initiating core with multi-functionality is synthesized first followed by the polymerization of a monomer from the core to obtain star polymers with defined numbers of arms. The resulting chain end of each arm can undergo subsequent chain extension with another monomer to afford star block copolymers. In the "arm-first" strategy, the reactive arms are synthesized first followed by facilely gathering the reactive site of the arms with cross-linkers to form star polymers. However, the resulting star polymers have a statistical distribution in the number of arms. A variety of star polymers were synthesized based on the aforementioned methods. In examples of the "grafting onto" strategy, efficient organic reactions of copper(I)-catalyzed alkyne-azide cycloaddition (CuAAC) reaction [30,31] and Diels-Alder (DA) reaction [32] were used to synthesize different types of star polymers. In examples of the "core-first" strategy, Huang et al. described the synthesis of tetra-functionalized adamantane initiator and proceeded with ATRP to obtain a PMMA star polymer [33]. The compatibility of linear and star PMMA with phenolic blends were investigated [34]. The same group developed hyperbranched core star polymers by using an active-site-transfer methodology in a one-pot manner [35]. Alonzo et al. reported a series of amphiphilic star block copolymers exhibiting cores of PSt and coronas of poly(2-vinyl pyridine) (P2VP) through sequential anionic polymerizations in a systematic kinetics preferential absorption method [36]. In examples of the "arm-first" strategy, Matyjazsewski et al. described the synthesis of PnBA-b-PtBA (i.e., $n$ - and tert-butyl acrylate) star block copolymers via ATRP with a ppm-level copper catalytic system [37]. Aimi and co-workers developed a non-volatile organic memory device based on organic field effect transistor (OFET) technique by using tetra-functionalized metallo-phthalocyanine (MPc) core to obtain polystyrene (PSt) four-arm star polymers via ATRP [38,39]. Grayer and co-workers described the synthesis of PSt first followed by growing the P2VP chain from the core to afford mikto-arm star ( $\mu$-star) copolymers of the $\mathrm{PSt}_{n} \mathrm{P}_{2} \mathrm{VP}_{\mathrm{n}}$ (i.e., $n=13$ and $40 \mathrm{arms}$ ) via anionic polymerization [40]. Kakuchi et al. synthesized $A_{3} B_{3}, A_{2}$, and $A_{3} \mu$-star copolymers and demonstrated their interesting physical properties [41-43]. Recently, we have reported novel miktoarm star copolymers containing poly( $\varepsilon$-caprolactone) (PCL) and poly( $N$-octyl benzamides) via subsequent CGCP, styrenics-assisted atom transfer radical coupling (SA ATRC), and ROP [44]. From the literature, manipulation/control of the aforementioned three methods are highly desired in order to pursue the synthesis of novel branched/star copolymers that might possess unique physical properties.

In this study, we develop a new strategy for the synthesis of PCL-based $\mu$-star copolymers. As shown in Scheme 1, we carry out the ROP of $\varepsilon$-caprolactone (CL) monomer followed by quantitative chain end modification to afford chain-end functionalization PCL-Br precursor via acylation with 2-bromoisobutyryl bromide. Then SA ATRC of PCL-Br with 4-vinylbenzyl chloride (VBC) was conducted to obtain mid-chain functionalized macroinitiator (PCL-VBC $\left.\mathrm{m}_{\mathrm{m}}-\mathrm{PCL} \mathrm{MI}\right)$. The PCL-VBC $\mathrm{m}-\mathrm{PCL}$ MI containing ATRP initiating groups of benzylic chloride subsequently was subjected to chain extensions with styrene (St) and tBA monomers to afford PCL-based $\mu$-star copolymers (i.e., PCL- $\mu$-PSt and PCL- $\mu$-PtBA). The physical properties of these copolymers were examined. 


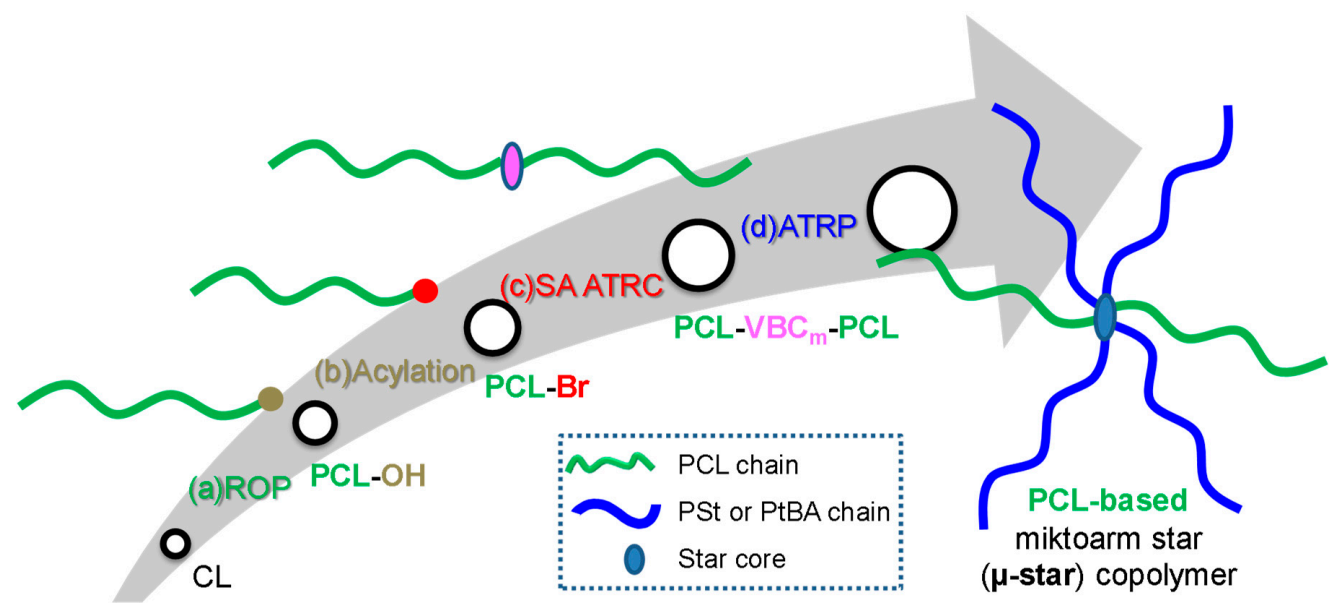

Scheme 1. Synthetic routes of poly( $\varepsilon$-caprolactone)-based $\mu$-star copolymers.

\section{Materials and Methods}

\subsection{Materials}

Copper powder $(\mathrm{Cu}(0), 99.5 \%, 150$ mesh), copper(I) chloride ( $\mathrm{CuCl}, 97 \%)$, copper(I) bromide $(\mathrm{CuBr}, 99 \%), N, N, N^{\prime}, N^{\prime \prime}, N^{\prime \prime}$-pentamethyldiethylenetriamine (PMDETA), alumina $\left(\mathrm{Al}_{2} \mathrm{O}_{3}\right.$ neutral), benzyl alcohol (BzOH), 4-vinylbenzyl chloride (VBC), styrene (St), and tert-butyl acrylate (tBA, 98\%) were purchased from Sigma-Aldrich (St. Louis, MO, USA) . 2-Bromoisobutyryl bromide (BiB, 97\%), $\varepsilon$-caprolactone (CL, 98\%), tin(II) 2-ethylhexanoate $\left(\mathrm{Sn}(\mathrm{oct})_{2}\right)$, and triethylamine (TEA, 99.5\%) were purchased from Acros (Geel, Belgium). All solvents and monomers were purified and stored with dried molecular sieves prior to use.

\subsection{ROP with $\varepsilon$-Caprolactone and Chain End Modification (Shown in Scheme 1a,b, respectively)}

An oven dried $100 \mathrm{~mL}$ Schlenk tube and magnetic stirrer bar with $\mathrm{BzOH}(0.83 \mathrm{~mL}, 8 \mathrm{mmol})$, CL $(8.86 \mathrm{~mL}, 80 \mathrm{mmol})$, and $\mathrm{Sn}(\mathrm{oct})_{2}(32.40 \mathrm{mg}, 0.08 \mathrm{mmol})$ were charged. The tube was sealed and deoxygenated using freeze-pump-thaw for three cycles and back refilled with $\mathrm{N}_{2}$. The set up was placed into preheated oil both at $120^{\circ} \mathrm{C}$ for $24 \mathrm{~h}$. The reaction mixture was cooled to room temperature in an ice bath, diluted with tetrahydrofuran (THF) and twice re-precipitated into cold methanol $(\mathrm{MeOH})$. The white powders were collected and dried under vacuum to afford poly( $\varepsilon$-caprolactone) with a hydroxyl chain end (PCL-OH; $M_{\mathrm{n}}=2500 \mathrm{~g} / \mathrm{mol}$ and PDI (i.e., $\left.M_{\mathrm{w}} / M_{\mathrm{n}}\right)=1.18\left(M_{\mathrm{n}} \equiv\right.$ number-average molecular weight and $M_{\mathrm{w}} \equiv$ weight-average molecular weight); yield =65\%).

A clean and dried $100 \mathrm{~mL}$ round-bottom flask was charged with PCL-OH (4.0 g, $1.25 \mathrm{mmol})$, TEA (1.76 mL, $12.5 \mathrm{mmol})$, and $40 \mathrm{~mL}$ of anhydrous dichloromethane (DCM) and cooled to $0{ }^{\circ} \mathrm{C}$ under $\mathrm{N}_{2}$ atmosphere. BiB (1.54 mL, $\left.12.5 \mathrm{mmol}\right)$ was diluted with anhydrous DCM and slowly added to the mixture by a cannula. After complete addition, the solution was stirred at ambient temperature for another $72 \mathrm{~h}$. The undissolved solid was removed by filtration and the resulting solution was quenched with saturated $\mathrm{NaHCO}_{3(\mathrm{aq})}$, subsequently washed with brine solution and then dried over $\mathrm{MgSO}_{4}$. The solvent was removed under reduced pressure, the obtained oily liquid was re-dissolved in THF. The solution was precipitated in cold $\mathrm{MeOH}$. The resulting solid was collected by filtration and dried under vacuum to yield poly( $\varepsilon$-caprolactone) bearing a terminal isobutyryl bromide group $\left(\mathrm{PCL}-\mathrm{Br} ; M_{\mathrm{n}}=3000 \mathrm{~g} / \mathrm{mol}\right.$ and PDI $=1.14 ;$ yield $=76 \%$ ).

\subsection{SA ATRC of PCL-Br with VBC (Shown in Scheme 1c)}

The coupling PCL-VBC $_{\mathrm{m}}$-PCL product was synthesized according to our previous report $[15,16,44]$. A typical synthetic procedure: A $25 \mathrm{~mL}$ Schlenk flask was charged with PCL-Br 
$(0.15 \mathrm{~g}, 0.05 \mathrm{mmol}), \mathrm{VBC}(110 \mu \mathrm{L}, 0.76 \mathrm{mmol})$, PMDETA $(30 \mu \mathrm{L}, 0.13 \mathrm{mmol})$ and dry toluene $(2.5 \mathrm{~mL})$. The mixture was deoxygenated using freeze-pump-thaw for three cycles. The mixture was frozen and back-filled with $\mathrm{N}_{2}$. CuBr $(7.3 \mathrm{mg}, 0.05 \mathrm{mmol})$ and $\mathrm{Cu}$ powder $(19.3 \mathrm{mg}, 0.3 \mathrm{mmol})$ were added into the flask, proceeded with two additional freeze-pump-thaw cycles and then sealed the flask. At ambient temperature an initial sample was taken via a syringe to trace the coupling reaction. After completion of the reaction, the flask was placed in an ice bath and exposed with ambient atmosphere and the crude product was diluted with THF and passed through a neutral $\mathrm{Al}_{2} \mathrm{O}_{3}$ column. The solution was concentrated under vacuum and twice precipitated into cold $\mathrm{MeOH}$. The resulting white powder was collected and dried under vacuum to afford a poly( $\varepsilon$-caprolactone) with mid-chain functionality of benzylic chlorides ( $\mathrm{PCL}-\mathrm{VBC} \mathrm{m}_{\mathrm{m}}-\mathrm{PCL} ; M_{\mathrm{n}}=5700 \mathrm{~g} / \mathrm{mol}$ and $\mathrm{PDI}=1.18$; yield $=79 \%$ ).

\subsection{Chain Extension of PCL-VBC ${ }_{m}-P C L$ with St or tBA through ATRP (Shown in Scheme 1d)}

An example for ATRP with tBA: an oven dried $25 \mathrm{~mL}$ Schlenk tube were charged with PCL-VBC $\mathrm{m}_{\text {-PCL }}(0.05 \mathrm{~g}, 0.018 \mathrm{mmol}), \mathrm{tBA}(0.53 \mathrm{~mL}, 3.63 \mathrm{mmol})$, PMDETA $(3.8 \mu \mathrm{L}, 0.02 \mathrm{mmol})$, and anisole $(0.53 \mathrm{~mL})$. The tube was sealed using a rubber septa and filled with nitrogen. The mixture was degassed by means of freeze-pump-thaw cycles and then back-filled with nitrogen. $\mathrm{CuCl}(1.8 \mathrm{mg}$, $0.02 \mathrm{mmol}$ ) was added and the tube was sealed with a glass stopper. The mixture was kept at $70^{\circ} \mathrm{C}$ in a thermostated oil bath. An initial sample was taken and the chain extension was periodically traced by GPC. After reaction completed, the mixture was diluted with THF and passed through a neutral $\mathrm{Al}_{2} \mathrm{O}_{3}$ column to remove the catalyst. The resulting solution was concentrated under vacuum and precipitated into $\mathrm{MeOH}$. The obtained light-yellowish sticky solid was collected and dried under vacuum to afford a miktoarm star copolymer (PCL- $\mu-\mathrm{PtBA}: M_{\mathrm{n}}=37,000 \mathrm{~g} / \mathrm{mol}, \mathrm{PDI}=1.50$, yield $=70 \%$ ).

\subsection{Deprotection of $P C L-\mu-P t B A$}

A $10 \mathrm{~mL}$-flask equipped was dried, purged with nitrogen, and charged with PCL- $\mu$-PtBA (100 mg) and dry DCM $(5 \mathrm{~mL})$. TFA $(2 \mathrm{~mL})$ was added and the mixture was stirred at room temperature for $24 \mathrm{~h}$ to remove the tert-butyl group. The concentrated crude product was dissolved in DCM and precipitated into hexane to obtain afford PCL- $\mu$-PAA a yellowish-white viscos liquid (32 mg, yield 60\%).

\subsection{Characterization}

Gel permeation chromatography (GPC) was performed at $40{ }^{\circ} \mathrm{C}$ in tetrahydrofuran (THF) with a flow rate of $1 \mathrm{~mL} / \mathrm{min}$, containing a Waters 515 pump, a Waters 486 absorbance detector, a Waters 410 differential refractometer, and two PSS SDV columns (Linear S and $100 \AA$ pore size). The characterization of $M_{\mathrm{n}}, M_{\mathrm{W}}$, and PDI (i.e., $M_{\mathrm{w}} / M_{\mathrm{n}}$ ) was estimated by monodisperse polystyrene (PSt) standards. Proton nuclear magnetic resonance $\left({ }^{1} \mathrm{H}\right.$ NMR) measurements were conducted by using a Bruker $500 \mathrm{NMR}$ in $\mathrm{CDCl}_{3}$ and the chemical shift was rectified by setting the internal standard of $\mathrm{CDCl}_{3}$ as $7.26 \mathrm{ppm}$. FT-IR spectra were analyzed by a Nicolet Avatar 320 FT-IR Spectrometer with 16 scans at a resolution of $2 \mathrm{~cm}^{-1}$. The dissolved samples were drop-casted onto a $\mathrm{KBr}$ disk and dried under vacuum before FT-IR analysis. Matrix-assisted laser desorption/ionization time-of-flight mass spectrometry (MALDI-TOF MS) were recorded on a Bruker Autoflex III spectrometer plus in the reflectron ion mode. 2-(4-Hydroxyphenylazo)benzoic acid (HABA) was used as the matrix with sodium chloride $(\mathrm{NaCl})$ as the cationizing salt for the MALDI-TOF mass measurements. The glass transition temperature $\left(T_{\mathrm{g}}\right)$ of the polymers was measured by a Seiko 6220 differential scanning calorimetry (DSC) with a protocol as follows: raising temperature from 25 to $150{ }^{\circ} \mathrm{C}$, keeping $3 \mathrm{~min}$ isothermal at $150^{\circ} \mathrm{C}$, and quenching the samples by liquid nitrogen were pre-treated. Then the thermal traces were recorded by heating the sample from 0 to $150{ }^{\circ} \mathrm{C}$ (ramp $20^{\circ} \mathrm{C} / \mathrm{min}$ ) under nitrogen. Thermogravimetric analysis (TGA) of the samples was measured by a TA Instruments Q50 analyzer (scan rate: $20^{\circ} \mathrm{C} / \mathrm{min}$; from 100 to $800{ }^{\circ} \mathrm{C}$ under nitrogen) with a platinum holder. Atomic force microscopy (AFM) was conducted using a Seiko SPA400 microscope. Clearly well-dissolved solutions of pure and $\mu$-star (co)polymer $\left(1 \mathrm{wt} \%\right.$ in $\left.\mathrm{CH}_{2} \mathrm{Cl}_{2}\right)$ were drop-casted onto silicon wafers; after the 
solvent evaporated, the samples were annealed overnight above their $T_{\mathrm{g}}$ under vacuum. The height and phase images were recorded and accompanied with the height difference $(\Delta \mathrm{H}(\mathrm{nm}))$ and tapping angle phase difference $\left(\Delta \operatorname{deg}\left({ }^{\circ}\right)\right)$ individually.

\section{Results and Discussion}

Several examples of using the efficient convergent method of styrenics-assisted atom transfer radical coupling (SA ATRC) were demonstrated for the synthesis of block, macrocyclic, and miktoarm star ( $\mu$-star) copolymers $[15,16,44-46]$. Herein, we combine the SA ATRC with ring-opening polymerization (ROP) and atom transfer radical polymerization (ATRP) to synthesize unique PCL-based $\mu$-star copolymers. Figure 1 shows the gel permeation chromatography (GPC) results of (a) PCL-OH, (b) PCL-Br, and (c) PCL-VBC $\mathrm{m}_{\mathrm{m}} \mathrm{PCL}$ corresponding to after ROP with CL, chain end modification, and after SA ATRC, respectively. Comparison of the curves for $1 \mathrm{a}$ and $1 \mathrm{~b}$ reveals that the molecular weight (MW) had shifted slightly from 2500 to $3000 \mathrm{~g} / \mathrm{mol}$ with low PDI values after acylation of PCL-OH chain end. After SA ATRC of PCL-Br with VBC (curve c: $\mathrm{VBC} / \mathrm{PCL}-\mathrm{Br} / \mathrm{CuBr} / \mathrm{Cu}(0) / \mathrm{PMDETA}=15 / 1 / 1 / 6 / 2.5$ at $\left.25{ }^{\circ} \mathrm{C}\right), M_{\mathrm{n}}$ increased to approximately $5700 \mathrm{~g} / \mathrm{mol}$ with still remaining a low PDI value (1.18). According to the literature [15,47], the extent of coupling $\left(x_{\mathrm{c}}=2 \times\left(1-M_{\mathrm{n}, 0} / M_{\mathrm{n}}\right)\right.$ where $M_{\mathrm{n}, 0}$ is the initial number-average molecular weight and $M_{\mathrm{n}}$ is the value after coupling) was estimated. The trace $\mathrm{c}$ in Figure 1 has a high $x_{\mathrm{c}}$ value of approximately 0.94 with a monomodal MW distribution, implying the high efficiency of SA ATRC at low temperature. The corresponding polymers were analyzed by ${ }^{1} \mathrm{H}$ NMR spectroscopy. Figure 2a shows the sample of PCL-OH. The representative signals of PCL repeating units (i.e., peaks $b-f$ ) were assigned and the signals from the chain ends were obviously observed (i.e., peaks $t$, a, and $f^{\prime}(\sim 7.38,5.10$, and 3.65 ppm, respectively)). After acylation of PCL-OH, the disappearance of peak $\mathrm{f}^{\prime}$ and appearance of peak $\mathrm{g}(\sim 1.88 \mathrm{ppm})$ were shown in Figure $2 \mathrm{~b}$, indicating a quantitative chain end modification to afford PCL-Br. After SA ATRC of PCL-Br with VBC, the disappearance of peak $g$ and appearance of peaks $i$ and $\mathrm{j}$ ( 4.59 and $7.05 \mathrm{ppm}$, respectively) were revealed in Figure 2c, implying the occurrence of the convergent reaction that inserted a small amount of VBC.

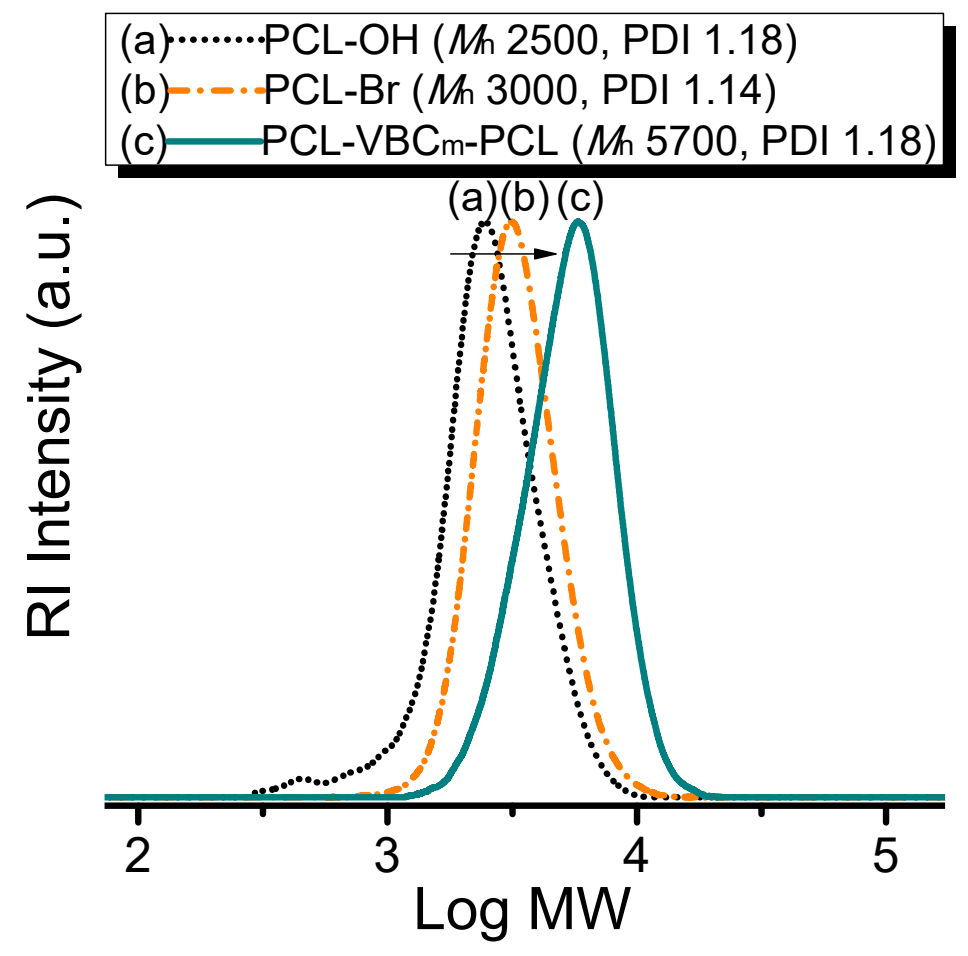

Figure 1. GPC traces (RI detector) of (a) PCL-OH, (b) PCL-Br, and (c) PCL-VBC $\mathrm{m}^{-P C L}$. 


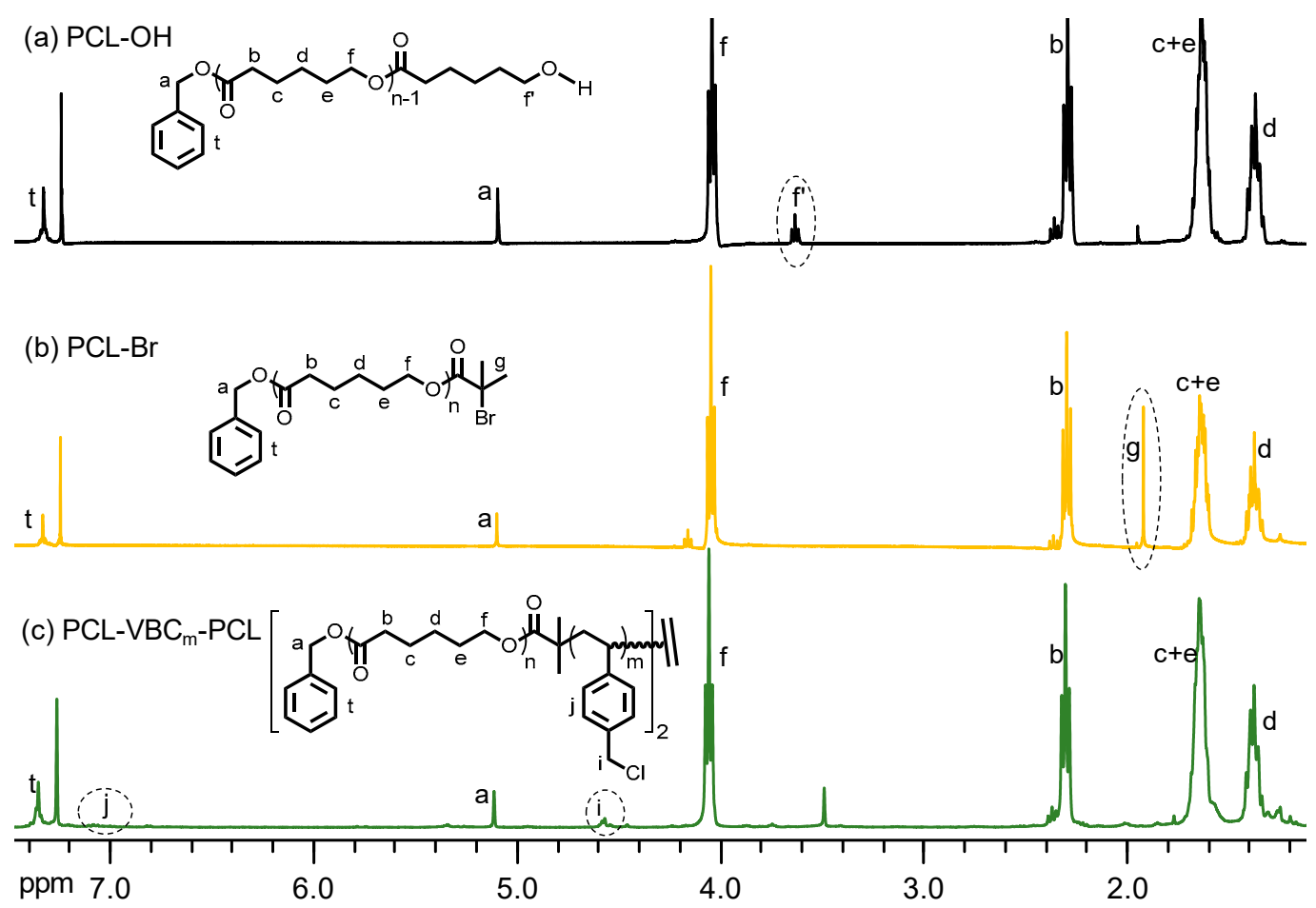

Figure 2. ${ }^{1} \mathrm{H}$ NMR spectra $\left(400 \mathrm{MHz}, \mathrm{CDCl}_{3}\right)$ of (a) PCL-OH, (b) PCL-Br, and (c) PCL-VBC $\mathrm{m}-\mathrm{PCL}$.

To further understand the chemical structures obtained after SA ATRC, the precursor (PCL-Br) and coupling polymer (PCL-VBC $\left.\mathrm{m}_{-} \mathrm{PCL}\right)$ were analyzed by MALDI-TOF MS using 2-(4-hydroxyphenylazo)benzoic acid (HABA) as the matrix. Accordingly, we can avoid the influence of the remained precursor on the estimation of the chemical structure. Figure 3a shows the MALDI-TOF spectrum of PCL-Br $\left(M_{\mathrm{n}}=3000 \mathrm{~g} / \mathrm{mol}\right.$, PDI = 1.14), indicating a series of peaks separated by approximately $114.1 \mathrm{Da}$, which correspond to the molar mass of the PCL repeating unit. Taking an example of the peak of $m / z=1420.2(\mathrm{n}=11)$, the initial benzylic group of PCL-Br was lost and hydrogenated (i.e., $m / z=$ head $\left(\mathrm{MW}_{\text {hydroxyl }}=17\right)+\mathrm{n} \times$ units $\left(\mathrm{MW}_{(\mathrm{n} \times \mathrm{CL})}=11 \times 114.1\right)+$ end $\left.\left(\mathrm{MW}_{\text {tertiary bromoester }}=149.9\right)=1421.9\right)$. In MALDI-TOF measurements, chain-end cleavages are commonly acquired due to the formation of unstable ions that fragment after acceleration in the ion source region $[48,49]$. With the addition of $\mathrm{NaCl}$ as the cationizing salt, Figure $3 \mathrm{~b}$ shows the MALDI-TOF spectrum of PCL-VBC $\mathrm{m}_{\mathrm{m}} \mathrm{PCL}\left(M_{\mathrm{n}}=5700 \mathrm{~g} / \mathrm{mol}\right.$, PDI $\left.=1.18\right)$ that also displays a series of peaks corresponding to the PCL repeating unit (ca. $114 \mathrm{Da}$ ). Taking an example of the peak at $m / z=2405.5(\mathrm{n}=14)$, a coupling product with four VBC inserted units was revealed (i.e., $\mathrm{m} / \mathrm{z}=$ chain-ends $\left(\mathrm{MW}_{\text {hydroxyls }}=17 \times 2\right)+$ mid-links $\left(\mathrm{MW}_{\text {tertiary esters }}=70 \times 2\right)+n \times$ units $\left(\mathrm{MW}_{(\mathrm{n} \times \mathrm{CL})}\right.$ $=14 \times 114)+\mathrm{m} \times$ inserted units $\left.\left(\mathrm{MW}_{(\mathrm{m} \times \mathrm{VBC})}=4 \times 152.6\right)+\mathrm{Na}^{+}(22.9)=2404.9\right)$. The estimated and measured $\mathrm{m} / \mathrm{z}$ values with different $\mathrm{m}$ units of were summarized and compared in Table S1. With the aid of the styrenics as a coupling agent (herein: VBC), high efficiency of SA ATRC for the synthesis of mid-chain functionalized polymers with benzylic chlorides was attained. Our proposed mechanisms of the SA ATRC reaction are illustrated in Scheme S1 and Table S2. The rate constants of activation, deactivation, and termination of PCL-Br were presumably similar to that of nature of ethyl 2-bromoisobutyrate (EBiB) and methyl methacrylate (MMA) due to structural analogy of tertiary bromoester (i.e., $k_{\mathrm{a}, \mathrm{EBiB}}, k_{\mathrm{da}, \mathrm{EBiB}}$, and $k_{\mathrm{t}, \mathrm{MMA}}$, respectively). In the presence of $\mathrm{VBC}$, the rate constants were presumably similar to that of benzylic chloride (BzCl), 1-phenyl ethylbromide ( $\mathrm{PEBr}$ ) and styrene (St) (i.e., $k_{\mathrm{a}, \mathrm{BzCl}}, k_{\mathrm{da}, \mathrm{BzCl}}, k_{\mathrm{a}, \mathrm{PEBr}}, k_{\mathrm{da}, \mathrm{PEBr}}$, and $k_{\mathrm{t}, \mathrm{St}}$, respectively). With the absence of $\mathrm{VBC}$, the generated methacrylic macroradical (PCL $\bullet$ ) preferred the termination of disproportionation as illustrated in schemes (ES1) and (ES2) and species I and II were obtained as major products. 
In the presence of VBC, the PCL macroradical was led to fast addition of VBC. Then the termination mechanism switched from scheme (ES2) to schemes (ES3-ES7). To achieve high coupling efficiency, four successive factors are satisfied [50,51]: (1) moderate equilibrium constant value in scheme (ES1) $\left(K_{\mathrm{EBiB}} \sim 10^{-7}\right.$ ) provides efficient activation/deactivation reactions at low temperature and prolongs the radical life-time; (2) rapid formation of species III results from a fast addition rate of methacrylic radical to VBC in scheme (ES3) $\left(k_{\mathrm{i}} \sim 5 \times 10^{3} \mathrm{M}^{-1} \mathrm{~s}^{-1}\right)$; (3) negligible occurrence of scheme (ES4) arises from the activation rate from the benzylic chloride moiety is much lower than that of the phenyl alkylbromide moiety in the dormant species of PCL-VBC-Br (i.e., $k_{\mathrm{a}, \mathrm{PEBr}}\left(\sim 8.8 \times 10^{-2}\right) / k_{\mathrm{a}, \mathrm{BzCl}}$ $\left.\left(\sim 2.9 \times 10^{-3}\right)=30\right)$. (4) At low temperature, the concentration of $\mathrm{VBC}\left([\mathrm{VBC}]_{0}=0.3 \mathrm{M}\right)$ and propagation rate constant $\left(k_{\mathrm{p}, \mathrm{VBC}} \sim 170 \mathrm{M}^{-1} \mathrm{~s}^{-1}\right)$ should be sufficiently low to avoid eminent chain extension (i.e., the $x$ value of species IV in scheme (ES5) is small). With the nature of the styrene radical termination in scheme ES6, fast recombination was mainly conducted $\left(k_{\mathrm{t}, \mathrm{St}} \sim 10^{8} \mathrm{M}^{-1} \mathrm{~s}^{-1}\right)$ and formed

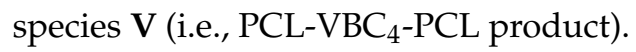

(a) PCL-Br

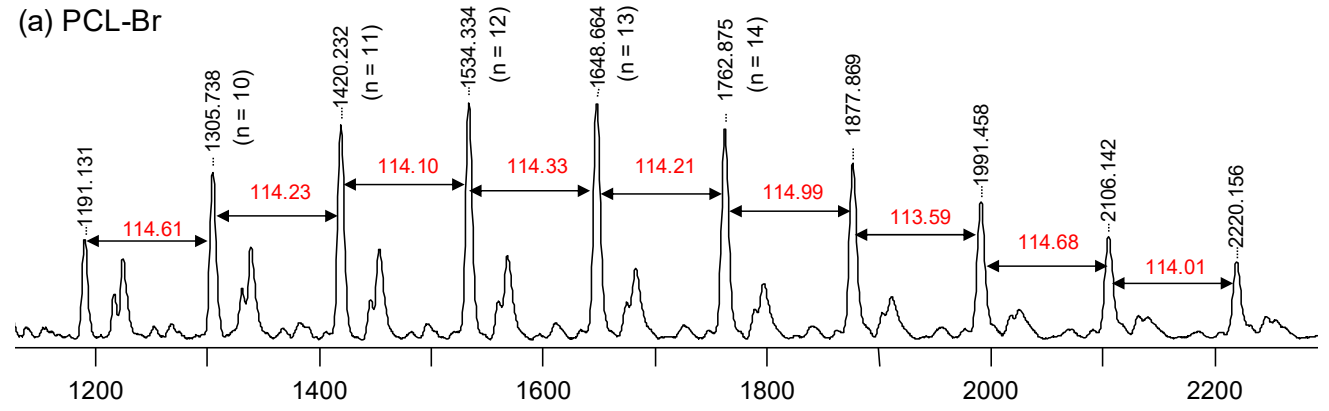

(b) PCL-VBC - PCL

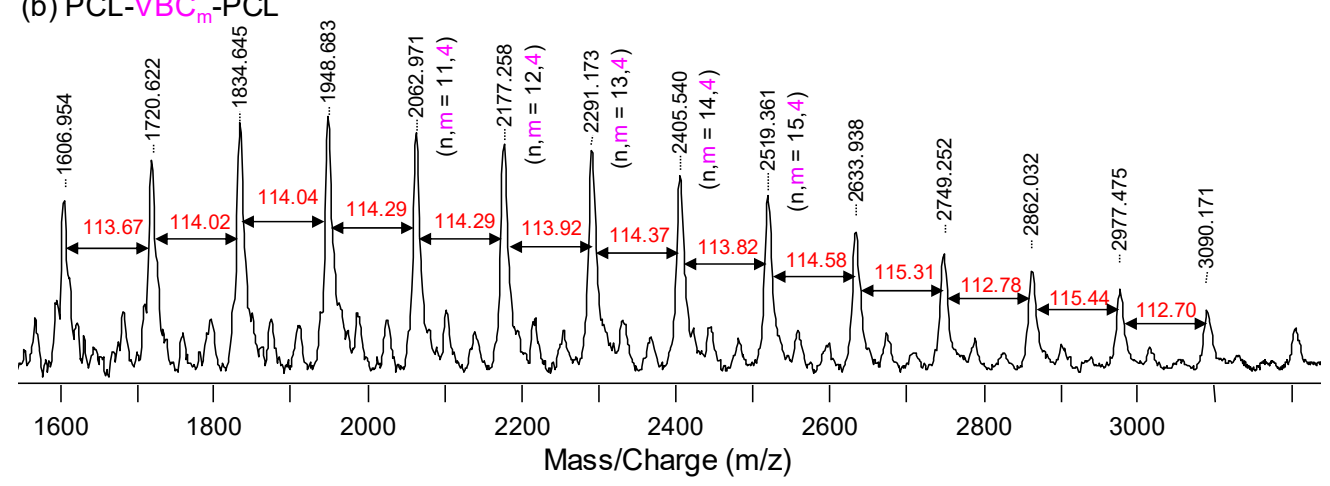

Figure 3. MALDI-TOF MS of (a) PCL-Br and (b) PCL-VBC $m$-PCL polymers (n: repeating units of CL).

The obtained PCL-VBC 4 -PCL polymer was then used as a macroinitiator (MI) for chain extensions through ATRP from the mid-chain functional moiety of benzylic chlorides. Generally, a first order kinetic is examined to interpret the living polymerization fashion through a $\operatorname{Ln}$ vs. $t$ plot (i.e., $\operatorname{Ln}\left(\mathrm{M}_{0} / \mathrm{M}\right)$ $=k_{\mathrm{app}} \mathrm{t}$ where $\mathrm{M}_{0}$ is the initial concentration of monomer, $\mathrm{M}$ is the concentration of monomer at time, and $k_{\text {app }}$ is the apparent reaction rate constant that is the multiplication of propagation rate constant and concentration of the propagating radical (i.e., $k_{\mathrm{app}}=k_{\mathrm{p}}[\mathrm{M} \bullet]$ ]) [26]. Figure $4 \mathrm{~A}$ demonstrates the kinetic plot of the chain extension with St monomer $\left(\mathrm{St} / \mathrm{PCL}-\mathrm{VBC}_{4}-\mathrm{PCL} / \mathrm{CuCl} / \mathrm{PMDETA}=\right.$ $500 / 1 / 1 / 1$ in anisole at $70{ }^{\circ} \mathrm{C} ;[\mathrm{St}]_{0}=4.3 \mathrm{M}$ ). A first-order kinetic plot showed a linear relationship with a $k_{\text {app }}$ value of approximately $4.67 \times 10^{-6} \mathrm{~s}^{-1}$. Figure $4 \mathrm{~B}$ displays the GPC traces of the corresponding periods of reaction time. A gradual growth of MWs (values of $M_{n}$ increased from $5.8 \mathrm{k}$ to $17 \mathrm{k} \mathrm{g} / \mathrm{mol})$ with monomodal traces and low PDIs $(<1.4)$ were observed during the chain extension. The results indicated a typical controlled/living radical polymerization fashion and we successfully synthesized $\mathrm{PCL}_{2}-\mu$-PSt $t_{4}$ miktoarm star copolymers. Figure $5 \mathrm{~A}$ displays the kinetic plot of the chain extension with $\mathrm{tBA}$ monomer $\left(\mathrm{tBA} / \mathrm{PCL}^{-V_{B C}}-\mathrm{PCL} / \mathrm{CuCl} / \mathrm{PMDETA}=200 / 1 / 1 / 1\right.$ in anisole 
at $\left.70{ }^{\circ} \mathrm{C} ;[\mathrm{tBA}]_{0}=3.4 \mathrm{M}\right)$. A first-order kinetic plot showed a linear relationship with a $k_{\text {app }}$ value of approximately $5.72 \times 10^{-5} \mathrm{~s}^{-1}$ that is approximately an order magnitude faster than that of the St case. Due to the fast propagation rate of $\mathrm{tBA}$ at $70^{\circ} \mathrm{C}\left(k_{\mathrm{p}, \mathrm{BA}} \sim 4.2 \times 10^{4} \mathrm{M}^{-1} \mathrm{~s}^{-1}\right)$, however, a gradual growth of MWs $\left(M_{\mathrm{n}} \sim 7.3 \mathrm{k}-32 \mathrm{k} \mathrm{g} / \mathrm{mol}\right)$ with bimodal traces and high PDIs $(>1.81)$ was obtained. Meanwhile, with chain extension, the lower MW peaks with nearly stationary was ascribed to the presence of MI that possesses low activation rate constant at $70{ }^{\circ} \mathrm{C}\left(k_{\mathrm{a}, \mathrm{BzCl}} \sim 1.8 \times 10^{-2} \mathrm{M}^{-1} \mathrm{~s}^{-1}\right)$ [51]. At the later stage of chain extension, eventually, a $\mathrm{PCL}_{2}-\mu-\mathrm{PtBA}_{4}$ miktoarm star copolymer was obtained $\left(M_{n}\right.$ $\sim 32 \mathrm{~kg} / \mathrm{mol}$ and PDI $=1.53$ ).
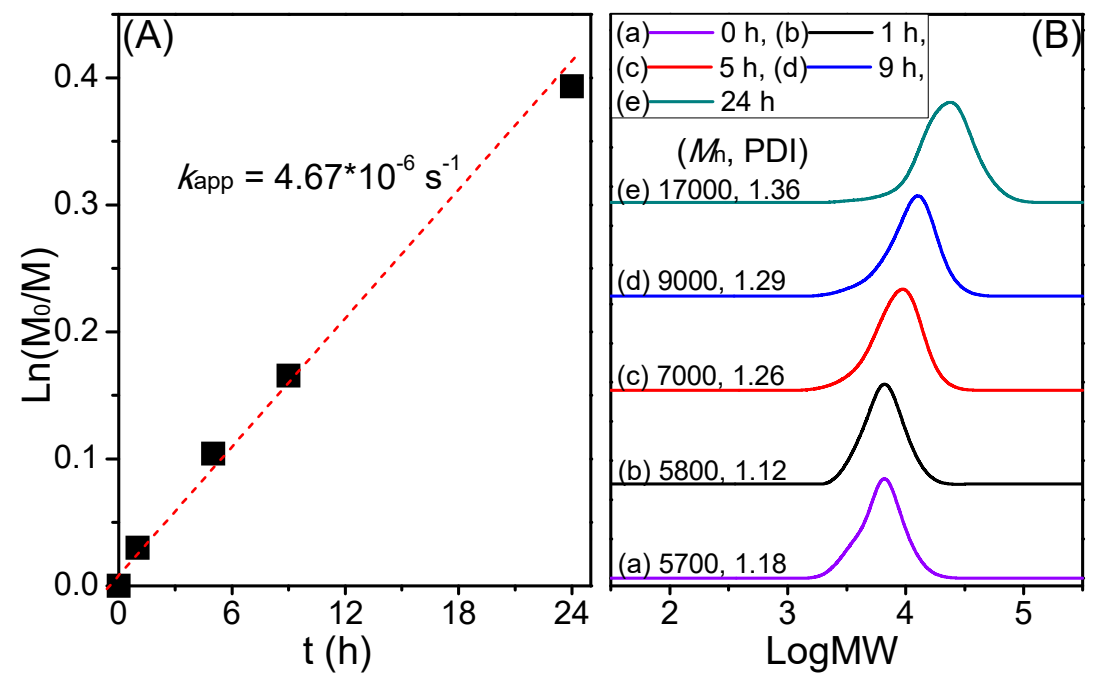

Figure 4. Chain extension of PCL-VBC 4 -PCL with St of (A) kinetic plots and (B) GPC traces (eluent: THF).
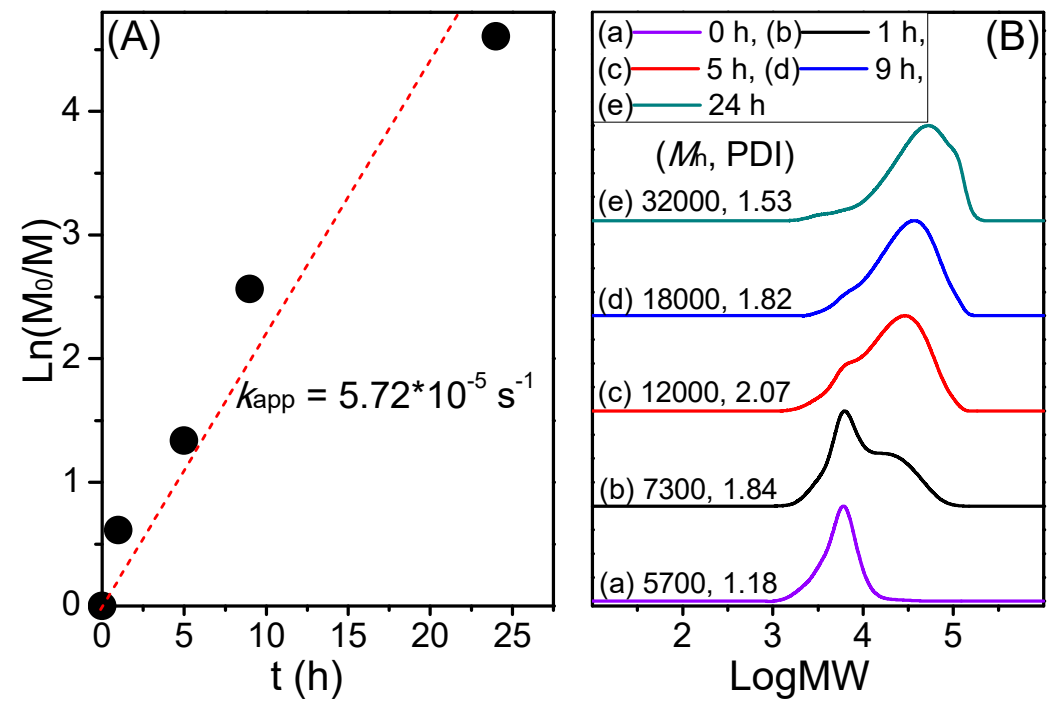

Figure 5. Chain extension of $\mathrm{PCL}-\mathrm{VBC}_{4}-\mathrm{PCL}$ with tBA of (A) kinetic plots and (B) GPC traces (eluent: THF).

The resulting products of PCL- $\mu$-PSt and PCL- $\mu$-PtBA were subjected to structural elucidation by using ${ }^{1} \mathrm{H}$ NMR spectroscopy. Figure 6a shows the spectrum of PCL-VBC $\mathrm{m}_{\mathrm{m}}-\mathrm{PCL}$ MI that possesses methylene group of peak i ( 4.5 ppm). In PCL- $\mu$-PSt (Figure $6 \mathrm{~b}$ ), besides the representative signals from the PCL backbone, the disappearance of peak $i$ and appearance of peaks Ar, $h$, and $g$ from phenyl ring and PSt backbone ( 6.6-7.1, 1.7, 1.2 ppm, respectively) were acquired. In PCL- $\mu$-PtBA (Figure 6c), 
similarly, the disappearance of peak $i$ and appearance of peaks $q, p$, and $k$ from PtBA backbone $(\sim 2.1$, 1.6, 1.4 ppm, respectively) were obtained. FT-IR spectra of the PCL, PCL- $\mu$-PSt, and PCL- $\mu$-PtBA were shown in Figure S1. The results supported the chain extensions of PSt and PtBA chains from the PCL-VBC ${ }_{\mathrm{m}}$-PCL MI.
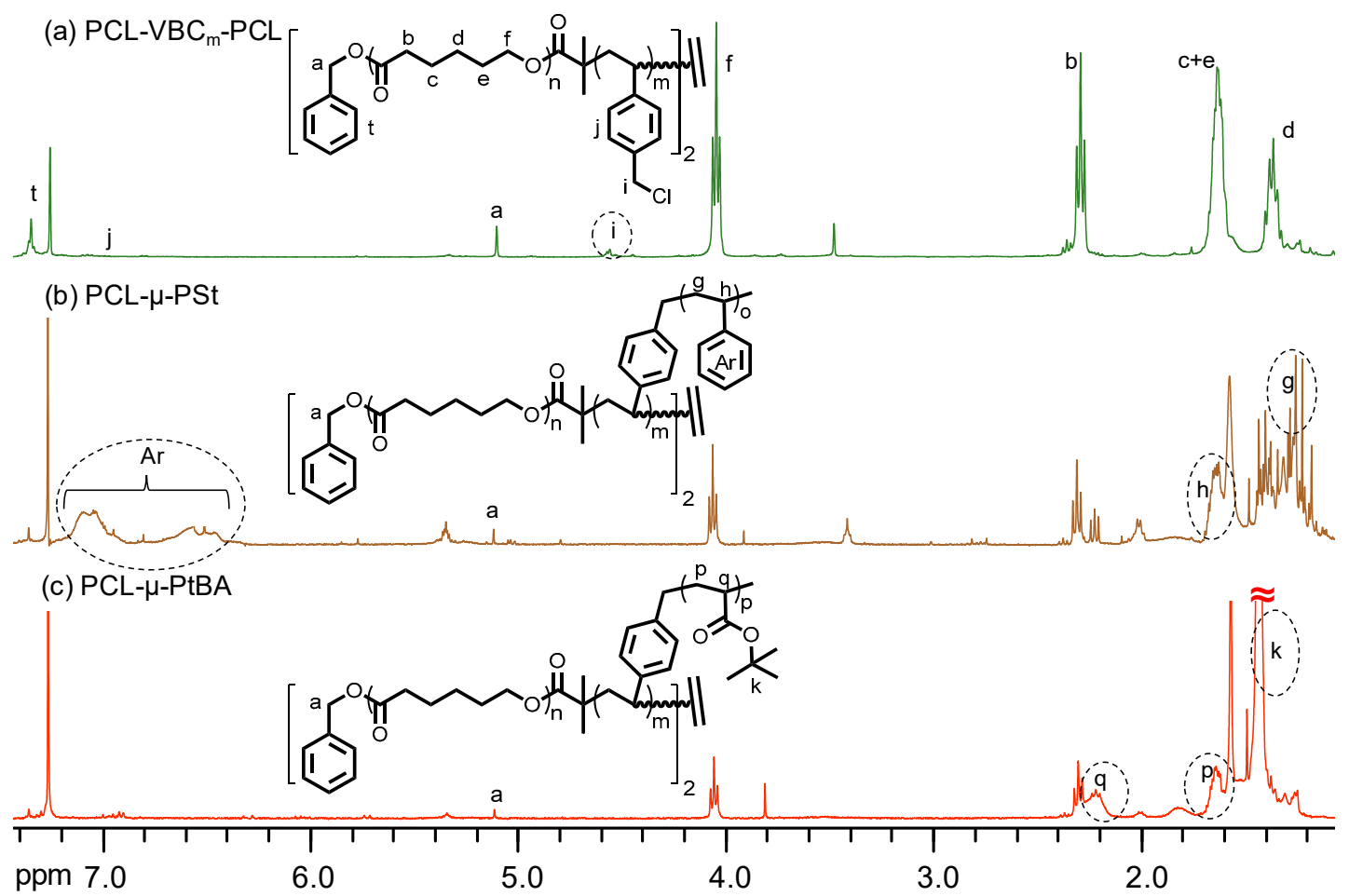

Figure 6. ${ }^{1} \mathrm{H}$ NMR spectra $\left(400 \mathrm{MHz}, \mathrm{CDCl}_{3}\right.$ ) of (a) PCL-VBC $\mathrm{m}-\mathrm{PCL},(\mathbf{b}) \mathrm{PCL}-\mu-\mathrm{PSt}$, and (c) PCL- $\mu-\mathrm{PtBA}$ (co)polymers.

Thermal properties of the $\mu$-star copolymers were measured by differential scanning calorimetry (DSC) and thermogravimetric analysis (TGA) with a heating rate of $20{ }^{\circ} \mathrm{C} / \mathrm{min}$ under nitrogen. Figure 7 shows the two-run DSC traces of the PCL- $\mu$-PSt and PCL- $\mu$-PtBA copolymers. In the first runs of PCL- $\mu$-PSt and PCL- $\mu$-PtBA (solid lines of a and c), the $T_{\mathrm{g}} \mathrm{s}$ of PSt and PtBA chains were respectively observed at approximately 81 and $38^{\circ} \mathrm{C}$. In addition, the $T_{\mathrm{m}}$ peak of PCL with low intensity can be also detected at approximately $57^{\circ} \mathrm{C}$ in each case, indicating the presence of PCL crystalline in the PCL- $\mu$-PSt and PCL- $\mu$-PtBA star copolymers. In the second runs (dash lines of $b$ and $\mathrm{d}$ ), the $T_{\mathrm{g}} \mathrm{s}$ of PSt and PtBA chains were still observed but the $T_{\mathrm{m}}$ of PCL was disappeared in each case. Before the second run, notably, the samples were heated to $150^{\circ} \mathrm{C}$ and quenching to $0{ }^{\circ} \mathrm{C}$. With a fast quenching step, the disappearance of melting behavior indicated a slow crystallization rate of PCL segments, resulting from the nature of the star polymer with restricted chain mobility [52]. Figure 8 displays the TGA analysis of the PCL- $\mu$-PSt and PCL- $\mu$-PtBA copolymers. The temperature of $5 \mathrm{wt} \%$ loss of sample $\left(T_{\mathrm{d} 5 \%}\right)$ were both approximately $150{ }^{\circ} \mathrm{C}$ in curves a and b in Figure $8 \mathrm{~A}$. Then, we further differentiated the traces to comprehend the degrading steps in each curve. In curve a of Figure $8 \mathrm{~B}$, the first degradation peak was ca. $190{ }^{\circ} \mathrm{C}$ and the second degradation peak was ca. $450{ }^{\circ} \mathrm{C}$ which were mainly due to the degradation of PCL and PSt segments, respectively. In curve $b$ of Figure $8 \mathrm{~B}$, a three-step degradation behavior was observed (ca. 160, 250, and $400{ }^{\circ} \mathrm{C}$ ), indicating the corresponding degradations of the PCL segment, tert-butyl group, and PtBA backbone, respectively. Thermal properties of these miktoarm star copolymers are summarized in Table 1. 


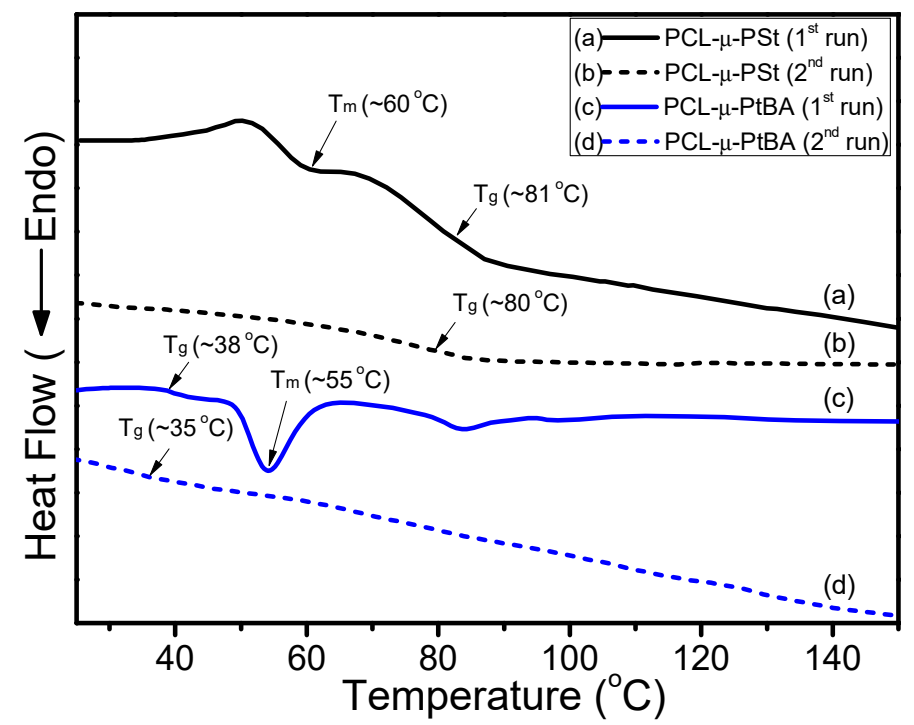

Figure 7. DSC traces of $(\mathbf{a}, \mathbf{b})$ PCL- $\mu$-PSt and $(\mathbf{c}, \mathbf{d})$ PCL- $\mu$-PtBA star copolymers $(\mathbf{a}, \mathbf{c}$ : first run and $\mathbf{b}, \mathbf{d}$ : second run).

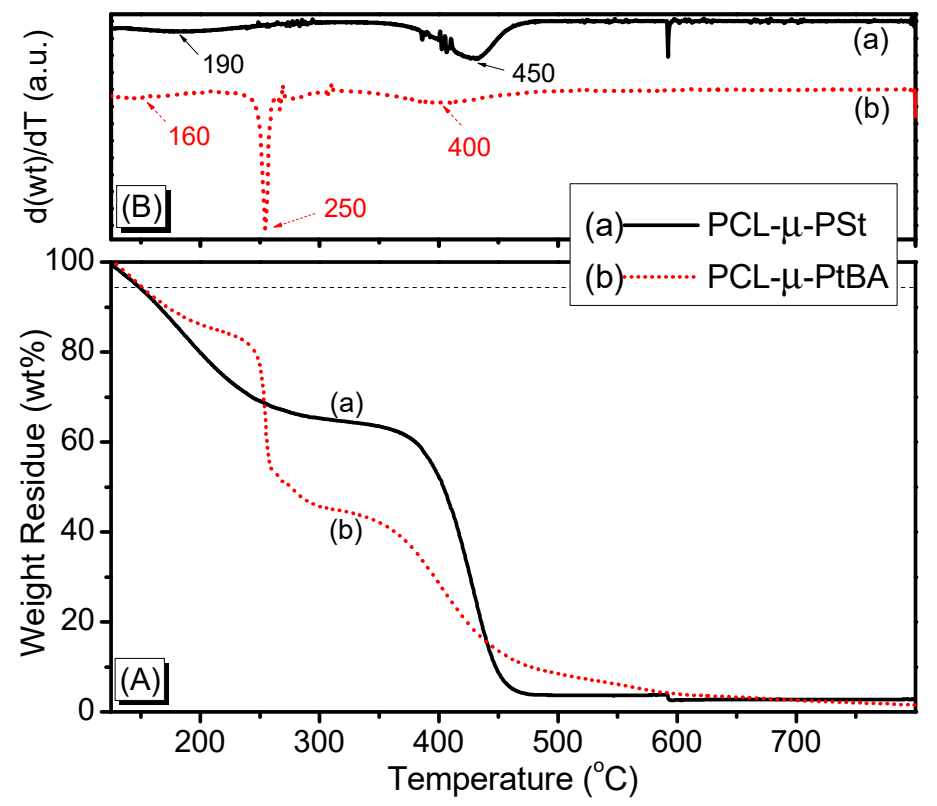

Figure 8. TGA (A) and DTGA (B) traces of (a) PCL- $\mu$-PSt and (b) PCL- $\mu$-PtBA star copolymers.

Table 1. Summary of thermal properties of $\mu$-star copolymers.

\begin{tabular}{cccccc}
\hline Sample & $\boldsymbol{T}_{\mathrm{g}}\left({ }^{\circ} \mathrm{C}\right)$ & $\boldsymbol{T}_{\mathrm{m}}\left({ }^{\circ} \mathrm{C}\right)$ & $\boldsymbol{x}_{\mathrm{c}}(\mathbf{\%})^{\mathbf{a}}$ & $\boldsymbol{T}_{\mathrm{d} 5 \%}\left({ }^{\circ} \mathrm{C}\right)$ & Char Yield (wt \%) \\
\hline First run & & & & & \\
PCL- $\mu$-PSt & 81 & 60 & 5.5 & 150 & 2.8 \\
PCL- $\mu-P t B A$ & 40 & 55 & 2.6 & 151 & 1.2 \\
\hline Second run & & & & & - \\
PCL- $\mu$-PSt & 80 & n.d. ${ }^{\mathbf{b}}$ & n.d. & - & - \\
PCL- $\mu$-PtBA & 36 & n.d. & n.d. & - & \\
\hline
\end{tabular}

a $x_{\mathrm{c}}(\%)=$ percentage of crystallinity $=\Delta H_{\mathrm{m}} / \Delta H_{\mathrm{m}}{ }^{\mathrm{o}}$ where $\Delta H_{\mathrm{m}}$ is the experimental melting enthalpy of the samples and $\Delta H_{\mathrm{m}}{ }^{\mathrm{o}}$ is the standard melting enthalpy of the pure PCL $(\sim 136 \mathrm{~J} / \mathrm{g})$ [53]. ${ }^{\mathrm{b}} T_{\mathrm{d} 5 \%}=$ temperature of $5 \mathrm{wt} \%$ sample loss. ${ }^{c}$ n.d. $=$ none detected. 
Miktoarm star polymers were then dissolved in $\mathrm{CH}_{2} \mathrm{Cl}_{2}(2 \mathrm{wt} \%)$ and drop-casted onto silicon wafers to examine their topology by using AFM. Figure 9 demonstrated the topological difference of PCL and PCL- $\mu$-PSt (co)polymers with height $(\mathrm{H})$ and phase $(\mathrm{P})$ images. In pure PCL (Figure $9 \mathrm{a})$, the images displayed morphological heterogeneity in their height and phase. The difference was because of the amorphous and crystalline macrophases of PCL. In the PCL- $\mu$-PSt copolymer (Figure 9b), an interesting nanoparticle morphology with an average diameter of approximately $250 \mathrm{~nm}$ was obtained. The presence of nanoparticles presumably resulted from the self-assembly of the PCL- $\mu$-PSt copolymer. On the other hand, the tert-butyl groups of the PCL- $\mu$-PtBA copolymer were subjected to deprotection with the use of TFA (trifluoroacetic acid) to afford PCL- $\mu$-PAA (PAA: polyacrylic acid) copolymer. FT-IR of the resulting copolymers were shown Figure S2. Figure 10 displayed the AFM results of PCL- $\mu$-PtBA and PCL- $\mu$-PAA copolymers. In the PCL- $\mu$-PtBA copolymer (Figure 10a), morphology of nanoparticles with an average diameter of approximately $45 \mathrm{~nm}$ were obtained, indicating the self-assembly of the PCL- $\mu-\mathrm{PtBA}$ copolymer. In the PCL- $\mu-\mathrm{PSt}$ and PCL- $\mu-\mathrm{PtBA}$ copolymers, similar sphere shapes were both observed in the height and phase images which were ascribed to mainly observe the outer shell by using AFM. More detailed characterization of the miktoarm star polymers are currently underway. After deprotection, the height and phase images showed a flat and smooth surface due to the good miscibility of the PCL and PAA segments as shown in Figure 10b. We propose self-assembly microstructures of the miktoarm star block copolymers based on AFM studies. In the PCL- $\mu$-PSt and PCL- $\mu$-PtBA copolymers, each possesses incompatible segments and the PCL segment tends to undergo crystallization-driven aggregation. Figure 11 shows the schematically proposed representations of self-assembled microstructure from immiscible segments and homogeneous surface from miscible segments. As shown in Figure 11A, namely, the assembled nanostructures were comprising the semi-crystal PCL chains as the inner part and PSt or PtBA as the external part. High homogeneity of PCL and PAA blends through intermolecular hydrogen bonding has been reported [54]. In the PCL- $\mu$-PAA, the results illustrated a homogenous surface of the miktoarm star copolymer (Figure 11B).
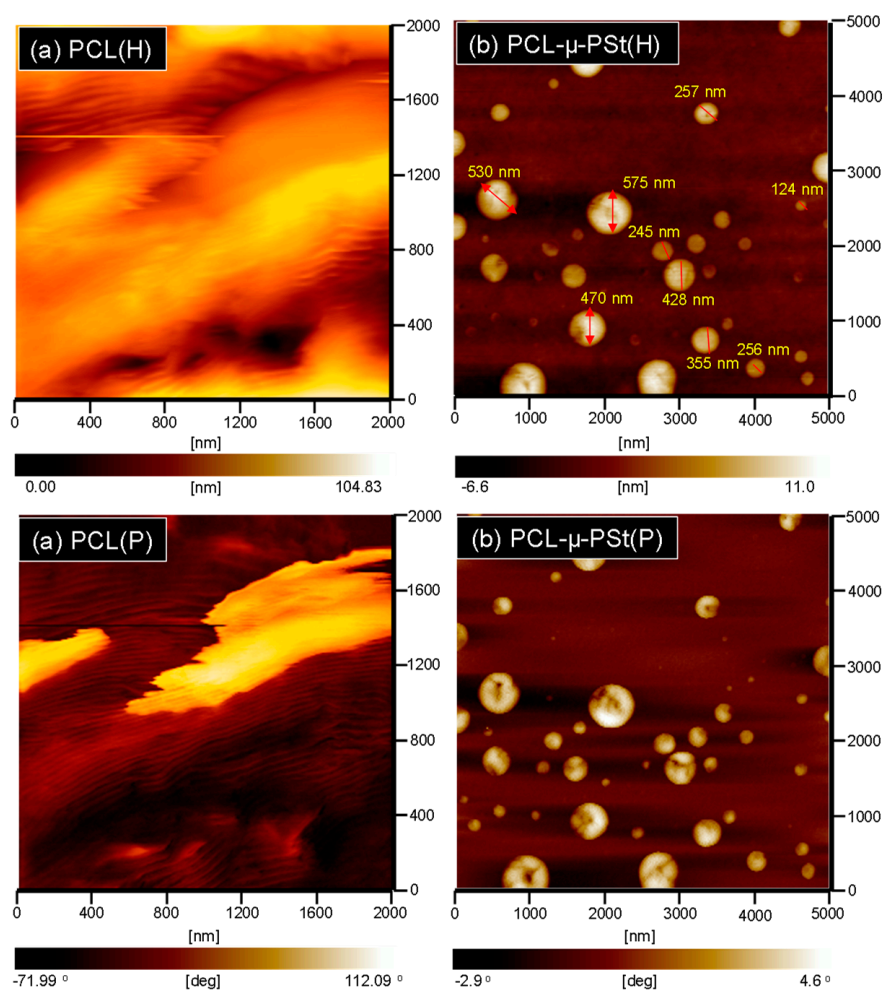

Figure 9. AFM images of (a) PCL and (b) PCL- $\mu$-PSt (co)polymers (H: height and P: phase). 

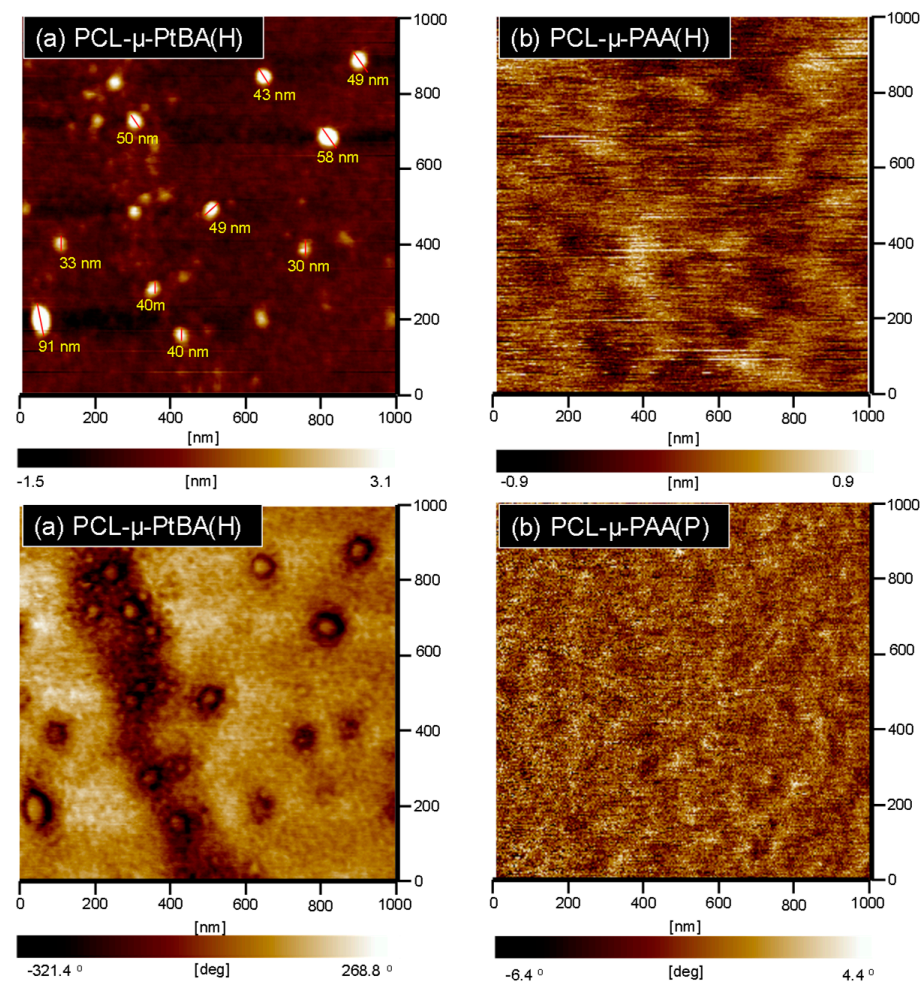

Figure 10. AFM images of (a) PCL- $\mu-P t B A$ and (b) PCL- $\mu-P A A$ star copolymers (H: height and P: phase).

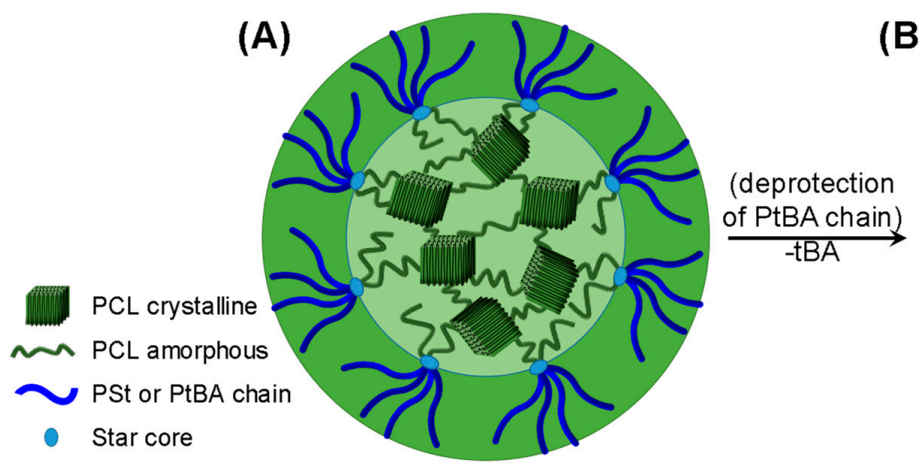

(B) Homogeneous (PCL- $\mu-P A A)$

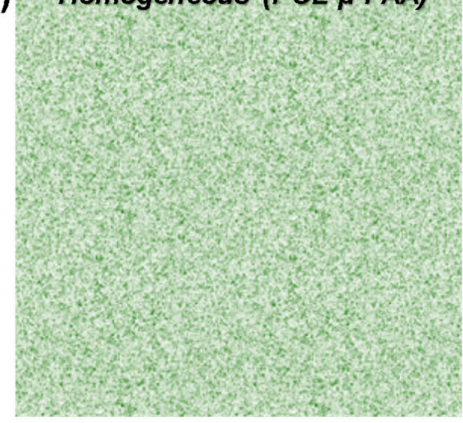

Figure 11. Proposed self-assembled microstructures of $\mu$-star copolymers: schematic representation of (A) self-assembled microstructure from immiscible segments and (B) homogeneous surface from miscible segments.

\section{Conclusions}

With the obtainment of quantitative chain-end-modification, high coupling efficiency $\left(x_{\mathrm{c}} \sim 0.94\right)$ of SA ATRC of PCL-Br with mono-modal MW distribution was successfully achieved with the aid of VBC at low temperature (VBC/PCL-Br/CuBr/Cu/PMDETA $=15 / 1 / 1 / 6 / 2.5$ at $\left.25^{\circ} \mathrm{C}\right)$. From the

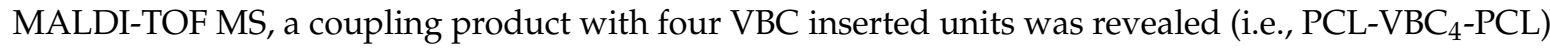
that can be rationally explained by the proposed SA ATRC mechanisms. By further proceeding with chain extensions of $\mathrm{PCL}_{-} \mathrm{VBC}_{4}$-PCL with St and tBA monomers via ATRP, controlled/living radical polymerization fashions were achieved and afforded unique $\mathrm{PCL}_{2}-\mu-\mathrm{PSt}_{4}$ and $\mathrm{PCL}_{2}-\mu-\mathrm{PtBA}_{4}$ six-arm star copolymers. Through DSC analysis, the $T_{\mathrm{g}}$ of amorphous segment and the $T_{\mathrm{m}}$ of PCL segment were detected for each $\mu$-star copolymer in the first run, indicating the presence of semi-crystal PCL. However, the $T_{\mathrm{m}}$ of PCL was both disappeared in the second run that was rationally resulted from the 
nature of the star polymer with restricted chain mobility. Through TGA analysis, a multistep degrading profile was detected which was ascribed to the subsequent degradations of the different analogue of arms. By further conducting AFM measurements, the morphology of the pure PCL demonstrated obvious heterogeneity due to the amorphous and crystal macrophases. In PCL- $\mu$-PSt and PCL- $\mu$-PtBA copolymers, interesting nanoparticles were observed with an average diameter of approximately 250 and $45 \mathrm{~nm}$, respectively. After deprotection of the tert-butyl group from the PCL- $\mu$-PtBA copolymer, AFM images showed a flat and smooth surface which was due to the good miscibility of PCL and PAA segments. We herein showed facial and effective combinations of ROP, SA ATRC, and ATRP to synthesize PCL-based $\mu$-star copolymers.

Supplementary Materials: The following are available online at http:/ /www.mdpi.com/2073-4360/10/8/858/s1, Table S1: Various inserted VBC units after SA ATRC of PCL-Br: estimated (Cal.) and measured (Exp.) $m / z$ values in Figure 3, Table S2: Summary of rate constants based on initiators of EBiB, $\mathrm{BzCl}$, and PEBr and monomers of MMA and St, Scheme S1: Reaction mechanisms of SA ATRC, Figure S1: FT-IR spectra of (a) PCL, (b) PCL- $\mu$-PSt, and (c) PCL- $\mu$-PtBA (co)polymers, Figure S2: FT-IR spectra of (a) PCL, (b) PCL- $\mu$-PtBA, and (c) PCL- $\mu$-PAA (co)polymers.

Author Contributions: C.-F.H. and Z.-C.C. conceived and designed the experiments; Z.-C.C. and V.S. performed the experiments; J.-K.C., C.-J.C., Y.-S.H., and C.-F.H. analyzed the data; V.S., J.A., and Y.-C.H. designed and contributed analysis tools of FT-IR and AFM; V.S. and C.-F.H. wrote the paper.

Funding: This research was funded by the Ministry of Science and Technology, Taiwan grant number [(MOST105-2218-E-005-004 and MOST105-2628-E-005-003-MY3].

Acknowledgments: The authors thank the Ministry of Science and Technology for their financial support.

Conflicts of Interest: The authors declare no conflict of interest.

\section{References}

1. Bielawski, C.W.; Grubbs, R.H. Living ring-opening metathesis polymerization. Prog. Polym. Sci. 2007, 32, 1-29. [CrossRef]

2. Kamber, N.E.; Jeong, W.; Waymouth, R.M.; Pratt, R.C.; Lohmeijer, B.G.G.; Hedrick, J.L. Organocatalytic ring-opening polymerization. Chem. Rev. 2007, 107, 5813-5840. [CrossRef] [PubMed]

3. Mecerreyes, D.; Jerome, R.; Dubois, P. Novel macromolecular architectures based on aliphatic polyesters: Relevance of the coordination-insertion ring-opening polymerization. Adv. Polym. Sci. 1999, 147, 1-59.

4. Braunecker, W.A.; Matyjaszewski, K. Controlled/living radical polymerization: Features, developments, and perspectives. Prog. Polym. Sci. 2007, 32, 93-146. [CrossRef]

5. Hawker, C.J.; Bosman, A.W.; Harth, E. New polymer synthesis by nitroxide mediated living radical polymerizations. Chem. Rev. 2001, 101, 3661-3688. [CrossRef] [PubMed]

6. Kamigaito, M.; Ando, T.; Sawamoto, M. Metal-catalyzed living radical polymerization. Chem. Rev. 2001, 101, 3689-3745. [CrossRef] [PubMed]

7. Moad, G.; Rizzardo, E.; Thang, S.H. Radical addition-fragmentation chemistry in polymer synthesis. Polymer 2008, 49, 1079-1131. [CrossRef]

8. Sun, H.; Kabb, C.P.; Dai, Y.Q.; Hill, M.R.; Ghiviriga, I.; Bapat, A.P.; Sumerlin, B.S. Macromolecular metamorphosis via stimulus-induced transformations of polymer architecture. Nat. Chem. 2017, 9, 817-823. [CrossRef] [PubMed]

9. Dai, Y.Q.; Sun, H.; Pal, S.; Zhang, Y.L.; Park, S.; Kabb, C.P.; Wei, W.D.; Sumerlin, B.S. Near-ir-induced dissociation of thermally-sensitive star polymers. Chem. Sci. 2017, 8, 1815-1821. [CrossRef] [PubMed]

10. Sun, H.; Kabb, C.P.; Sumerlin, B.S. Thermally-labile segmented hyperbranched copolymers: Using reversible-covalent chemistry to investigate the mechanism of self-condensing vinyl copolymerization. Chem. Sci. 2014, 5, 4646-4655. [CrossRef]

11. Yokozawa, T.; Asai, T.; Sugi, R.; Ishigooka, S.; Hiraoka, S. Chain-growth polycondensation for nonbiological polyamides of defined architecture. J. Am. Chem. Soc. 2000, 122, 8313-8314. [CrossRef]

12. Yokozawa, T.; Ogawa, M.; Sekino, A.; Sugi, R.; Yokoyama, A. Chain-growth polycondensation for well-defined aramide. Synthesis of unprecedented block copolymer containing aramide with low polydispersity. J. Am. Chem. Soc. 2002, 124, 15158-15159. [CrossRef] [PubMed] 
13. Huang, C.F.; Yokoyama, A.; Yokozawa, T. Synthesis of polybenzamide- $b$-polystyrene block copolymer via combination of chain-growth condensation polymerization and atom transfer radical polymerization. J. Polym. Sci. Part A Polym. Chem. 2010, 48, 2948-2954. [CrossRef]

14. Huang, C.-F.; Chen, M.-J.; Lin, C.-H.; Chiang, Y.-W. Synthesis of well-defined poly(N-H benzamide-co- $N$-octyl benzamide)s and the study of their blends with nylon 6. Polymers 2017, 9, 172. [CrossRef]

15. Huang, C.-F.; Ohta, Y.; Yokoyama, A.; Yokozawa, T. Efficient low-temperature atom transfer radical coupling and its application to synthesis of well-defined symmetrical polybenzamides. Macromolecules 2011, 44, 4140-4148. [CrossRef]

16. Lai, K.-Y.; Huang, Y.-S.; Chu, C.-Y.; Huang, C.-F. Synthesis of poly(N-H benzamide)-b-poly(lauryl methacrylate)- $b$-poly( $N-\mathrm{H}$ benzamide) symmetrical triblock copolymers by combinations of CGCP, SARA ATRP, and SA ATRC. Polymer 2018, 137, 385-394. [CrossRef]

17. Hadjichristidis, N.; Pitsikalis, M.; Pispas, S.; Iatrou, H. Polymers with complex architecture by living anionic polymerization. Chem. Rev. 2001, 101, 3747-3792. [CrossRef] [PubMed]

18. Ito, S.; Goseki, R.; Ishizone, T.; Hirao, A. Synthesis of well-controlled graft polymers by living anionic polymerization towards exact graft polymers. Polym. Chem. 2014, 5, 5523-5534. [CrossRef]

19. Sawamoto, M. Modern cationic vinyl polymerization. Prog. Polym. Sci. 1991, 16, 111-172. [CrossRef]

20. Yagci, Y.; Reetz, I. Externally stimulated initiator systems for cationic polymerization. Prog. Polym. Sci. 1998, 23, 1485-1538. [CrossRef]

21. Chiefari, J.; Chong, Y.K.; Ercole, F.; Krstina, J.; Jeffery, J.; Le, T.P.T.; Mayadunne, R.T.A.; Meijs, G.F.; Moad, C.L.; Moad, G.; et al. Living free-radical polymerization by reversible addition-fragmentation chain transfer: The RAFT process. Macromolecules 1998, 31, 5559-5562. [CrossRef]

22. Huang, C.-F.; Hsieh, Y.-A.; Hsu, S.-C.; Matyjaszewski, K. Synthesis of poly(N-vinyl carbazole)-based block copolymers by sequential polymerizations of RAFT-ATRP. Polymer 2014, 55, 6051-6057. [CrossRef]

23. Huang, C.-F.; Nicolay, R.; Kwak, Y.; Chang, F.-C.; Matyjaszewski, K. Homopolymerization and block copolymerization of $\mathrm{N}$-vinylpyrrolidone by ATRP and RAFT with haloxanthate inifers. Macromolecules 2009, 42, 8198-8210. [CrossRef]

24. Huang, Y.-S.; Chen, J.-K.; Chen, T.; Huang, C.-F. Synthesis of PNVP-based copolymers with tunable thermosensitivity by sequential reversible addition-fragmentation chain transfer copolymerization and ring-opening polymerization. Polymers 2017, 9, 231. [CrossRef]

25. Kato, M.; Kamigaito, M.; Sawamoto, M.; Higashimura, T. Polymerization of methyl methacrylate with the carbon tetrachloride/dichlorotris-(triphenylphosphine)ruthenium(II)/methylaluminum bis(2,6-di-tert-butylphenoxide) initiating system: Possibility of living radical polymerization. Macromolecules 1995, 28, 1721-1723. [CrossRef]

26. Wang, J.-S.; Matyjaszewski, K. Controlled/living radical polymerization. Atom transfer radical polymerization in the presence of transition-metal complexes. J. Am. Chem. Soc. 1995, 117, 5614-5615. [CrossRef]

27. Gao, H.F.; Matyjaszewski, K. Synthesis of functional polymers with controlled architecture by CRP of monomers in the presence of cross-linkers: From stars to gels. Prog. Polym. Sci. 2009, 34, 317-350. [CrossRef]

28. Goseki, R.; Ito, S.; Matsuo, Y.; Higashihara, T.; Hirao, A. Precise synthesis of macromolecular architectures by novel iterative methodology combining living anionic polymerization with specially designed linking chemistry. Polymers 2017, 9, 470. [CrossRef]

29. Ren, J.M.; McKenzie, T.G.; Fu, Q.; Wong, E.H.H.; Xu, J.T.; An, Z.S.; Shanmugam, S.; Davis, T.P.; Boyer, C.; Qiao, G.G. Star polymers. Chem. Rev. 2016, 116, 6743-6836. [CrossRef] [PubMed]

30. Gao, H.F.; Matyjaszewski, K. Synthesis of star polymers by a combination of ATRP and the click coupling method. Macromolecules 2006, 39, 4960-4965. [CrossRef]

31. Whittaker, M.R.; Urbani, C.N.; Monteiro, M.J. Synthesis of 3-miktoarm stars and 1st generation mikto dendritic copolymers by "living" radical polymerization and click chemistry. J. Am. Chem. Soc. 2006, 128, 11360-11361. [CrossRef] [PubMed]

32. Inglis, A.J.; Sinnwell, S.; Davis, T.P.; Barner-Kowollik, C.; Stenzel, M.H. Reversible addition fragmentation chain transfer (RAFT) and hetero-diels-alder chemistry as a convenient conjugation tool for access to complex macromolecular designs. Macromolecules 2008, 41, 4120-4126. [CrossRef]

33. Huang, C.-F.; Lee, H.-F.; Kuo, S.-W.; Xu, H.; Chang, F.-C. Star polymers via atom transfer radical polymerization from adamantane-based cores. Polymer 2004, 45, 2261-2269. [CrossRef] 
34. Huang, C.-F.; Kuo, S.-W.; Lin, H.-C.; Chen, J.-K.; Chen, Y.-K.; Xu, H.; Chang, F.-C. Thermal properties, miscibility and specific interactions in comparison of linear and star poly(methyl methacrylate) blend with phenolic. Polymer 2004, 45, 5913-5921. [CrossRef]

35. Chen, Z.-C.; Chiu, C.-L.; Huang, C.-F. Tuning the solubility of copper complex in atom transfer radical self-condensing vinyl polymerizations to control polymer topology via one-pot to the synthesis of hyperbranched core star polymers. Polymers 2014, 6, 2552-2572. [CrossRef]

36. Alonzo, J.; Hinestrosa, J.P.; Mays, J.W.; Kilbey, S.M. Kinetics of preferential adsorption of amphiphilic star block copolymers that tether by their corona blocks at the solid/fluid interface. Macromolecules 2014, 47, 4048-4055. [CrossRef]

37. Ding, H.J.; Park, S.; Zhong, M.J.; Pan, X.C.; Pietrasik, J.; Bettinger, C.J.; Matyjaszewski, K. Facile arm-first synthesis of star block copolymers via ARGET ATRP with ppm amounts of catalyst. Macromolecules 2016, 49, 6752-6760. [CrossRef]

38. Aimi, J.; Lo, C.-T.; Wu, H.-C.; Huang, C.-F.; Nakanishi, T.; Takeuchi, M.; Chen, W.-C. Phthalocyanine-cored star-shaped polystyrene for nano floating gate in nonvolatile organic transistor memory device. Adv. Electron. Mater. 2016, 2, 1500300. [CrossRef]

39. Aimi, J.; Wang, P.-H.; Shih, C.-C.; Huang, C.-F.; Nakanishi, T.; Takeuchi, M.; Hsuehe, H.-Y.; Chen, W.-C. A star polymer with a metallo-phthalocyanine core as a tunable charge storage material for nonvolatile transistor memory devices. J. Mater. Chem. C 2018, 6, 2724-2732. [CrossRef]

40. Grayer, V.; Dormidontova, E.E.; Hadziioannou, G.; Tsitsilianis, C. A comparative experimental and theoretical study between heteroarm star and diblock copolymers in the microphase separated state. Macromolecules 2000, 33, 6330-6339. [CrossRef]

41. Isono, T.; Otsuka, I.; Kondo, Y.; Halila, S.; Fort, S.; Rochas, C.; Satoh, T.; Borsali, R.; Kakuchi, T. Sub-10 $\mathrm{nm}$ nano-organization in $\mathrm{AB}_{2}$ - and $\mathrm{AB}_{3}$-type miktoarm star copolymers consisting of maltoheptaose and polycaprolactone. Macromolecules 2013, 46, 1461-1469. [CrossRef]

42. Isono, T.; Otsuka, I.; Suemasa, D.; Rochas, C.; Satoh, T.; Borsali, R.; Kakuchi, T. Synthesis, self-assembly, and thermal caramelization of maltoheptaose-conjugated polycaprolactones leading to spherical, cylindrical, and lamellar morphologies. Macromolecules 2013, 46, 8932-8940. [CrossRef]

43. Otsuka, I.; Zhang, Y.; Isono, T.; Rochas, C.; Kakuchi, T.; Satoh, T.; Borsali, R. Sub-10 nm scale nanostructures in self-organized linear di- and triblock copolymers and miktoarm star copolymers consisting of maltoheptaose and polystyrene. Macromolecules 2015, 48, 1509-1517. [CrossRef]

44. Huang, C.F.; Aimi, J.; Lai, K.Y. Synthesis of novel $\mu$-star copolymers with poly(N-octyl benzamide) and poly( $\varepsilon$-caprolactone) miktoarms through chain-growth condensation polymerization, styrenics-assisted atom transfer radical coupling, and ring-opening polymerization. Macromol. Rapid Commun. 2017, 38, 1600607. [CrossRef] [PubMed]

45. Bunha, A.K.; Mangadlao, J.; Felipe, M.J.; Pangilinan, K.; Advincula, R. Catenated PS-PMMA block copolymers via supramolecularly templated ATRP initiator approach. Macromol. Rapid Commun. 2012, 33, 1214-1219. [CrossRef] [PubMed]

46. Arce, M.M.; Pan, C.W.; Thursby, M.M.; Wu, J.P.; Carnicom, E.M.; Tillman, E.S. Influence of solvent on radical trap-assisted dimerization and cyclization of polystyrene radicals. Macromolecules 2016, 49, 7804-7813. [CrossRef]

47. Sarbu, T.; Lin, K.Y.; Ell, J.; Siegwart, D.J.; Spanswick, J.; Matyjaszewski, K. Polystyrene with designed molecular weight distribution by atom transfer radical coupling. Macromolecules 2004, 37, 3120-3127. [CrossRef]

48. Jackson, A.T.; Bunn, A.; Priestnall, I.M.; Borman, C.D.; Irvine, D.J. Molecular spectroscopic characterisation of poly(methyl methacrylate) generated by means of atom transfer radical polymerisation (ATRP). Polymer 2006, 47, 1044-1054. [CrossRef]

49. Jackson, A.T.; Bunn, A.; Chisholm, M.S. Utilising matrix-assisted laser desorption/ionisation techniques for the generation of structural information from different end-group functionalised poly(methyl methacrylate)s. Polymer 2008, 49, 5254-5261. [CrossRef]

50. Fischer, H.; Radom, L. Factors controlling the addition of carbon-centered radicals to alkenes-an experimental and theoretical perspective. Angew. Chem. Int. Ed. 2001, 40, 1340-1371. [CrossRef] 
51. Tang, W.; Kwak, Y.; Braunecker, W.; Tsarevsky, N.V.; Coote, M.L.; Matyjaszewski, K. Understanding atom transfer radical polymerization: Effect of ligand and initiator structures on the equilibrium constants. J. Am. Chem. Soc. 2008, 130, 10702-10713. [CrossRef] [PubMed]

52. Sperling, L.H. Introduction to Physical Polymer Science; Wiley-Interscience: New York, NY, USA, 1986.

53. Tiptipakorn, S.; Keungputpong, N.; Phothiphiphit, S.; Rimdusit, S. Effects of polycaprolactone molecular weights on thermal and mechanical properties of polybenzoxazine. J. Appl. Polym. Sci. 2015, 132, 41915. [CrossRef]

54. Mabrouk, M.; Choonara, Y.E.; Kumar, P.; du Toit, L.C.; Pillay, V. The influence of lyophilized emugel silica microspheres on the physicomechanical properties, in vitro bioactivity and biodegradation of a novel ciprofloxacin-loaded PCL/PAA scaffold. Polymers 2016, 8, 232. [CrossRef]

C 2018 by the authors. Licensee MDPI, Basel, Switzerland. This article is an open access article distributed under the terms and conditions of the Creative Commons Attribution (CC BY) license (http:// creativecommons.org/licenses/by/4.0/). 